\title{
The Surgical Management Strategies in Congenital Pulmonary Airway Malformations: According to the Location of the Pulmonary Involvement
}

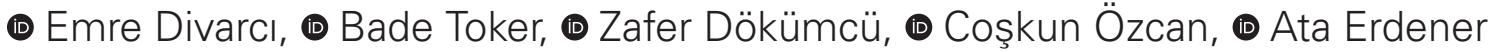 \\ Ege University Faculty of Medicine, Department of Pediatric Surgery, Izmir, Turkey
}

\begin{abstract}
Aim: Treatment of congenital pulmonary airway malformations (CPAMs) consists of different surgical options. In this study, we aimed to report our surgical management strategy according to the location of pulmonary involvement.

Materials and Methods: We retrospectively analyzed the medical records of patients who underwent surgery for CPAMs between 2005 and 2015 . The data including patient demographics, pre-operative clinical features, surgical management strategies and postoperative results were reviewed.

Results: Twenty patients (14 male, 6 female) with a median age of 4 months (1 day-12 years) were operated on. Antenatal diagnosis was positive in 12 patients (60\%). The other patients were admitted with a median age of 3.5 years ( 1 day- 12 years). Respiratory infection was seen in four patients ( $20 \%)$. Nine patients underwent early operation due to severe dyspnea and recurrent respiratory infection (45\%). Lobectomy was performed on 17 patients with single lobe involvement (85\%). Lobectomy for major lesion and segmentectomy for minor lesion was performed on two patients with unilateral multi-lobar involvement. One patient with bilateral multi-lobar involvement required multiple thoracoscopic wedge resections. Two patients who had severe dyspnea before surgery required mechanical ventilation after the operation, and one of them died. Two postoperative complications, empyema and pneumothorax were seen. Mean postoperative follow-up period was 5.5 years.

Conclusion: CPAMs must be excised totally due to the risk of pulmonary infection and malignancy. The resection strategy should be decided according to the number of the affected lobes. Lobectomy should be performed in single lobar involvement. Unilateral multi-lobar involvement requires lobectomy for a major lesion and segmentectomy for a minor one. Thoracoscopic multiple wedge resections should be the option in bilateral multi-lobar CPAMs.

Keywords: Congenital pulmonary airway malformation, congenital cystic adenomatoid malformation, lung cyst, children
\end{abstract}

\section{Introduction}

Congenital cystic adenomatoid malformations (CCAMs) are congenital lung malformations derived from a hamartomatous lesion of the bronchial tree (1). These lesions account for approximately $95 \%$ of congenital cystic lung diseases (2). In recent years the name of this clinical entity was changed to congenital pulmonary airway malformations (CPAMs). This new name has gained popularity and is primarily preferred in the current medical literature (3). The course of these lesions could be varied in a broad clinical spectrum as hydrops and fetal death due to rapid growing, or being asymptomatic without clinical problems $(4,5)$. Recurrent pulmonary infections, pnemumotorax and primary lung malignancies are the potential clinical problems which could be seen in the postnatal period $(6,7)$. Pulmonary blastoma, rabdomyosarcoma, bronchogenic carcinoma and various sarcomas were reported in the literature which got derived from CPAMs (8-11). Therefore, surgical resection is usually suggested to avoid these potential devastating clinical problems. Lobectomy is usually preferred in the surgical treatment of CPAMs in order to avoid leaving 
residual disease in the remaining lobe (3). However, the management of CPAMs could be a big challenge in patients with multilobar involvement. Formal lobectomies could result with pneumonectomy in these patients (12). In this study, we aimed to present our surgical management strategies in CPAMs according to the different locations of the pulmonary involvement.

\section{Materials and Methods}

The medical records of patients who underwent surgery for CPAMs between 2005 and 2015 were retrospectively analyzed. Data including age, time of clinical admission, respiratory problems, surgical resection strategies according to anatomic locations of the cystic lesions and postoperative complications were reviewed. The time of surgical resection was postnatal 1 to 6 months old in patients with antenatal diagnosis of CPAMs. However, early surgery was required in some of these patients in the early postnatal period due to severe respiratory defficiency. The other patients who were admitted after infancy period underwent elective surgical excision without any delay. The main surgical approach was thoracotomy. Thoracoscopy was preferred in only one patient with bilateral multi-lobar involvement. The surgical strategy was decided according to the anatomic location of the pulmonary involvement;

- Single lobar involvement: Lobectomy.

- Unilateral multi-lobar involvement: Lobectomy to the major lesion, segmentectomy to the minor.

- Bilateral multi-lobar involvement: Thoracoscopic wedge resections in multiple sessions.

All of the parents gave their informed consent prior to their inclusion in the study.

\section{Results}

Twenty patients (14 male, 6 female) with a median age of 4 months (range: 1 day-12 years) were operated on. The time of clinical admission was early postnatal period for 12 patients who had antenatal diagnosis (60\%). The other eight patients who had not had antenatal diagnosis were admitted with a median age of 3.5 years (range: 1 day-12 years). Main results are summarized in Table I. Pre-operative respiratory infection was seen in four patients (20\%). Nine patients underwent early operation due to severe dyspnea and recurrent respiratory infection (45\%). All of the patients were examined by computerized tomography after neonatal period as a routine pre-operative work-up. The most frequent location for pulmonary involvement was left lower lobe (40\%). The other locations were left upper lobe (20\%), right middle lobe (15\%), right upper lobe (10\%), unilateral multilobar (10\%), bilateral multilobar involvement $(5 \%)$ (Figure 1). Operative strategy was decided according to the location of the pulmonary involvement of the cystic lesions. Lobectomy was performed on 17 patients with single lobar involvement (85\%). Lobectomy to major cystic lesion and segmentectomy to minor lesion was performed in two patients with unilateral multi-lobar involvement (10\%). One patient with bilateral multi-lobar involvement required multiple thoracoscopic wedge resections (5\%) (Figure 2). Two patients who had severe dyspnea before surgery required mechanical ventilation after the operation. Mortality was seen in one of these patients due to severe respiratory insufficiency (5\%). Empyema and pneumothorax were two postoperative early complications which were treated succesfully. Recurrence, infection or malignancy was not observed in any of the

\begin{tabular}{|c|c|}
\hline \multicolumn{2}{|c|}{$\begin{array}{l}\text { Table I. The data of patient demographics and clinical features of } \\
\text { overall group }\end{array}$} \\
\hline Number of patients & 20 patients $(14 \mathrm{M}, 6 \mathrm{~F})$ \\
\hline Median age of operation & 4 months ( 1 day- 12 years) \\
\hline Antenatal diagnosis & $60 \%$ (12 patients) \\
\hline $\begin{array}{l}\text { Median admission age of patients without } \\
\text { antenatal diagnosis }\end{array}$ & 3.5 years (1 day- 12 years) \\
\hline \multicolumn{2}{|l|}{ Clinical presentations } \\
\hline $\begin{array}{l}\text { Asymptomatic }(n=8) \\
\text { Dyspnea }(n=6) \\
\text { Respiratory infections }(n=4)\end{array}$ & $\begin{array}{l}40 \% \\
30 \% \\
20 \%\end{array}$ \\
\hline $\begin{array}{l}\text { Early operation due to severe dyspnea } \\
\text { and recurrent respiratory infection }\end{array}$ & $45 \%$ (9 patients) \\
\hline \multicolumn{2}{|l|}{ Operative strategy } \\
\hline Single lobar involvement $(n=17)$ & Lobectomy \\
\hline Unilateral multi-lobar involvement $(n=2)$ & $\begin{array}{l}\text { Major lesion: Lobectomy } \\
\text { Minor lesion: Segmentectomy }\end{array}$ \\
\hline Bilateral multi-lobar involvement $(n=1)$ & $\begin{array}{l}\text { Thoracoscopic wedge } \\
\text { resections in multiple } \\
\text { sessions }\end{array}$ \\
\hline
\end{tabular}

F: Female, M: Male
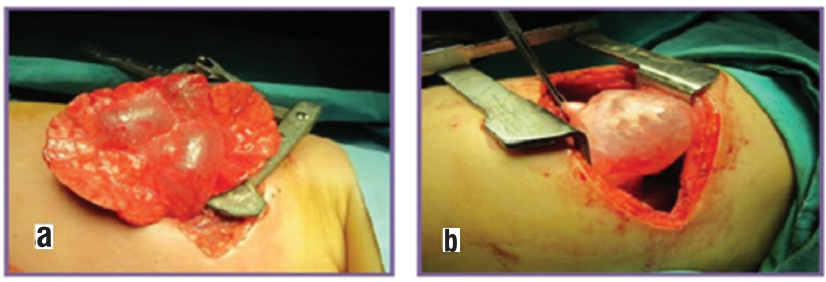

Figure 1. a) The lesion was identified in the right middle lobe and exteriorized through the thoracotomy incision. b) A huge cystic lesion was detected in the left upper lobe

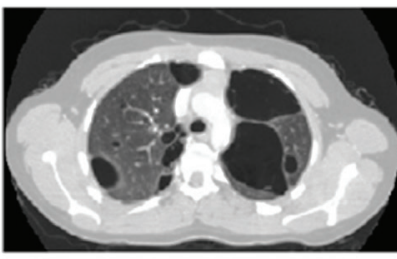

Preoperative CT scan

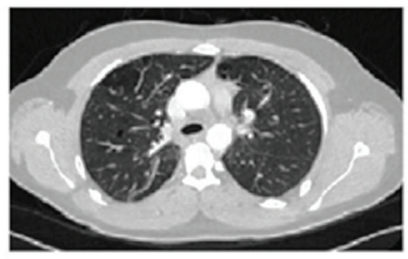

Postoperative control CT scan
Figure 2. Pre-operative and postoperative computed tomography scans of a patient with bilateral multi-lobar pulmonary involvement of cystic lesions

CT: Computed tomography 
patients during follow-up. Mean postoperative follow-up period was 5.5 years.

\section{Discussion}

The management strategies in CPAMs are usually based on potential detrimental clinical problems as recurrent pulmonary infections and rarely malignancy. A case was also reported from our clinic in recent years with primary pulmonary rhabdomyosarcoma arising within cystic adenomatoid malformation (11). Lobectomy is the most commonly preferred surgical technique to resect all of the cystic lesions to avoid residual disease. In recent years, nonoperative management with clinical follow-up has begun to be advocated in some of the centers due to the frequently benign asymptomatic course of these lesions $(13,14)$. However, the follow-up strategy is not clear. The interval periods between the radiological imaging studies and the type of the imaging modalities as computerized tomograghy or chest X-ray in the follow-up are not clearly defined in the literature, nor is the management strategy in patients with multi-lobar pulmonary involvement (12). Surgical excision is usually suggested to avoid potential clinical problems. Kapralik et al. (15) reported a systematic review and metaanalysis to discuss surgical versus conservative management of CPAMs in children. They suggested elective resection of asymptomatic lesions to avoid development of symptoms. Optimal age for surgery was not clearly defined in the reported studies. Naito et al. (16) reported that earlier lobectomy did not effect the pulmonary functions in the long-term. Sullivan et al. (17) discussed the optimal age for elective surgical resection for asymptomatic CPAMs with meta-analysis. They concluded that the current scientific evidence is not enough to suggest a conclusive recommendation for an optimal age for the timing of elective resection. We performed surgery in an earlier stage of infancy, namely 1-6 months old to reduce the risk of later complications like respiratory infections and pneumothorax (18). Formal lobectomy is the most commonly accepted surgical option for CPAMs in the current medical era (3) although in recent years some authors have suggested lung-sparing techniques such as segmentectomy by thoracoscopy for these lesions $(19,20)$. However, these strategies comprise an increased risk for an incomplete surgical excision. The risk of bringing residual disease was reported as 15\% after segmental resection (21). This approach should be rationale for salvaging from radical surgical resections such as pneumonectomy for multi-lobar or bilateral disease (22). In our study, we performed lobectomy for the major lesion and segmentectomy for the minor lesion in the left lobe to avoid pneumonectomy. In another patient with bilateral multilobar disease, we preferred multiple sessions of thoracoscopic wedge resections. We have not seen any recurrence or malignancy in the postoperative follow-up period. This surgical strategy which is based on the location of pulmonary involvement provides a safe and effective treatment option in bilateral and multilobar disease.
These patients should be followed by regular radiological imaging studies. We preferred chest X-rays with 3-monthintervals in the first postoperative year. A computerized tomography should be obtained at the end of the first year of postoperative period.

\section{Study Limitations}

Due to the retrospective nature of this study, there may have some limitations. Larger number of the patients should be more useful to evaluate the results of the operative strategies.

\section{Conclusion}

In conclusion, we suggested lobectomy for single lobar pulmonary involvement, and lobectomy for major lesion lesion; and segmentectomy for the minor lesion in unilateral multi-lobar involvement; and multiple thoracoscopic wedge resections for bilateral multi-lobar pulmonary involvement.

\section{Ethics}

Ethics Committee Approval: Retrospective study.

Informed Consent: All of the parents gave their informed consent prior to their inclusion in the study.

Peer-review: Externally peer-reviewed.

\section{Authorship Contributions}

Surgical and Medical Practices: E.D., Z.D., B.T., C.Ö., A.E., Concept: E.D., Design: E.D., Data Collection or Processing: B.T., Analysis or Interpretation: E.D., C.Ö., A.E., Literature Search: E.D., Z.D., Writing: E.D.

Conflict of Interest: None of the authors had conflict of interest.

Financial Disclosure: The authors declared that this study received no financial support.

\section{References}

1. Waszak P, Claris O, Lapillonne A, et al. Cystic adenomatoid malformation of the lung: neonatal management of 21 cases. Pediatr Surg Int 1999;15:326-31.

2. Cloutier MM, Schaeffer DA, Hight D. Congenital cystic adenomatoid malformation. Chest 1993;103:761-4.

3. Downard CD, Calkins CM, Williams RF, et al. Treatment of congenital pulmonary airway malformations: a systematic review from the APSA outcomes and evidence based practice committee. Pediatr Surg Int 2017;33:939-53.

4. Andrade CF, Ferreira HP, Fischer GB. Congenital lung malformations. J Bras Pneumol 2011;37:259-71.

5. Chuang S, Sugo E, Jaffe A. A review of postnatal management of congenital pulmonary airway malformations. Fetal Matern Med Rev 2009;20:179-204.

6. Sueyoshi R, Koga H, Suzuki K, et al. Surgical intervention for congenital pulmonary airway malformation (CPAM) patients with preoperative pneumonia and abscess formation: "open versus thoracoscopic lobectomy" Pediatr Surg Int 2016;32:347-51.

7. Attou R, Reper P. Complicated pneumothorax and congenital lung cystic malformation. Acta Clin Belg 2016:1-3. 
8. Summers RJ, Shehata BM, Bleacher JC, Stockwell C, Rapkin $\mathrm{L}$. Mucinous adenocarcinoma of the lung in association with congenital pulmonary airway malformation. J Pediatr Surg 2010;45:2256-9.

9. Andrassy RJ, Wiener ES, Raney RB, et al. Thoracic sarcomas in children. Ann Surg 1998;227:170-3.

10. Priest JR, Williams GM, Hill DA, Dehner LP, Jaffe A. Pulmonary cysts in early childhood and the risk of malignancy. Pediatr Pulmonol 2009;44:14-30.

11. Ozcan C, Celik A, Ural Z, Veral A, Kandiloglu G, Balik E. Primary pulmonary rhabdomyosarcoma arising within cystic adenomatoid malformation: A case report and review of the literatüre. J Pediatr Surg 2001;36:1062-5.

12. Ben-Ishay O, Nicksa GA, Wilson JM, Buchmiller TL. Management of giant congenital pulmonary airway malformations requiring pneumonectomy. Ann Thorac Surg 2012;94:1073-8.

13. Laberge JM, Puligandla P, Flageole H. Asymptomatic congenital lung malformations. Semin Pediatr Surg 2005; 14:16-33.

14. Ng C, Stanwell J, Burge DM, Stanton MP. Conservative management of antenatally diagnosed cystic lung malformations. Arch Dis Child 2014;99:432-7.

15. Kapralik J, Wayne C, Chan E, Nasr A. Surgical versus conservative management of congenital pulmonary airway malformation in children: A systematic review and metaanalysis. J Pediatr Surg 2016;51:508-12.
16. Naito $Y$, Beres A, Lapidus-Krol E, Ratjen F, Langer JC. Does earlier lobectomy result in better long-term pulmonary function in children with congenital lung anomalies? A prospective study. J Pediatr Surg 2012;47:852-6.

17. Sullivan KJ, Li M, Haworth $\mathrm{S}$, et al. Optimal age for elective surgery of asymptomatic congenital pulmonary airway malformation: a meta-analysis. Pediatr Surg Int 2017;33:66575.

18. Rothenberg SS. Cystic adenomatoid malformation. In: Parikd D, Crabbe D, Auldist AW, Rothenberg SS. Pediatric Thoracic Surgery, 1th ed. London, Springer-Verlag, 2009;391-8.

19. Rothenberg SS, Shipman K, Kay S, et al. Thoracoscopic segmentectomy for congenital and acquired pulmonary disease: a case for lung-sparing surgery. J Laparoendosc Adv Surg Tech A 2014;24:50-4.

20. Johnson SM, Grace N, Edwards MJ, Woo R, Puapong D. Thoracoscopic segmentectomy for treatment of congenital lung malformations. J Pediatr Surg 2011;46:2265-9.

21. Stanton M, Njere I, Ade-Ajayi N, Patel S, Davenport M. Systematic review and meta-analysis of the postnatal management of congenital cystic lung lesions. J Pediatr Surg 2009;44:1027-33.

22. Kim HK, Choi YS, Kim K, et al. Treatment of congenital cystic adenomatoid malformation: should lobectomy always be performed? Ann Thorac Surg 2008;86:249-53. 